\title{
Sintering behaviour of spinel-alumina composites
}

\author{
SOUMEN PAL, A K BANDYOPADHYAY, P G PAL*, S MUKHERJEE ${ }^{\dagger}$ and \\ B N SAMADDAR ${ }^{\dagger \dagger}$ \\ Department of Ceramic Technology, Govt. College of Engineering \& Ceramic Technology, Kolkata 700 010, India \\ ${ }^{\dagger}$ School of Material Science \& Technology, ${ }^{\dagger \dagger}$ Ex-emeritus Professor (AICTE), \\ Department of Metallurgical \& Material Engineering, Jadavpur University, Kolkata 700 032, India
}

MS received 21 July 2008

\begin{abstract}
Study of alumina-magnesia binary phase diagram reveals that around $40-50 \mathrm{wt} \%$ alumina dissolves in spinel $\left(\mathrm{MgAl}_{2} \mathrm{O}_{4}\right)$ at $1600^{\circ} \mathrm{C}$. Solid solubility of alumina in spinel decreases rapidly with decreasing temperature, which causes exsolution of alumina from spinel phase. Previous work of one of the authors revealed that the exsolution of alumina makes some interlocking structures in between alumina and spinel phases. In the present investigation, refractory grade calcined alumina and spinel powder were used to make different batch compositions. Green pellets, formed at a pressure of $1550 \mathrm{~kg} \mathrm{~cm} \mathbf{~ c}^{-2}$ were fired at different temperatures of $1500^{\circ}, 1550^{\circ}$ and $1600^{\circ} \mathrm{C}$ for $2 \mathrm{~h}$ soaking time. Bulk density, percent apparent porosity, firing shrinkage etc were measured at each temperature. Sintering results were analysed to understand the mechanism of spinel-alumina interactions. SEM study of present samples does not reveal the distinct precipitation of needle shaped $\alpha$-alumina from spinel, but has some effect on densification process of spinel-alumina composites. Microstructural differences between present and previous work suggest an ample scope of further work in spinel-alumina composites.
\end{abstract}

Keywords. Sintering; stoichiometric spinel; spinel-alumina composites; solid-solution.

\section{Introduction}

It is known for quite a long time that alumina-magnesia spinel with varying amounts of alumina and magnesia (either alumina-rich or magnesia-rich side) is a very important refractory material for various interesting applications in metallurgical and cement industries. This is due to the fact that the dense alumina-magnesia spinel has adequate 'hot strength', high 'corrosion resistance' to both acidic and basic slags, and also has good erosion resistance at elevated temperatures. The solid solubility of magnesia in alumina is very low $\left(100 \mathrm{ppm}\right.$ at $\left.1550^{\circ} \mathrm{C}\right)$, but its effect on the densification of alumina is remarkable. An addition of small amount $(0.2 \mathrm{wt} \%)$ of $\mathrm{MgO}$ in alumina stops secondary recrystallization of alumina and thereby helps alumina to attain its 'near theoretical density'. This fact has been interpreted by many workers (Coble 1961; Hener 1979; Burke et al 1980; Greskovitch and Anthony Brewer 2001) in various ways. Effect of spinel on sintering kinetics of alumina was studied by two of the authors (Paul and Samaddar 1985; Paul 1986) and showed that excess spinel beyond its solid solubility limit in alumina exists as second phase (spinel). The work also revealed that $\alpha$-alumina exsolved out as needle shaped precipitate forming inter-

\footnotetext{
*Author for correspondence (pgp1951@rediffmail.com)
}

locking structures. The latest $\mathrm{Al}_{2} \mathrm{O}_{3}-\mathrm{MgO}$ binary phase diagram (Kingery et al 1976) differs from that reported by Kingery in his first edition (Kingery 1960) in terms of solid solubility of $\mathrm{MgO}$ in $\mathrm{MgAl}_{2} \mathrm{O}_{4}$ spinel.

According to the latest diagram, $\mathrm{MgO}$ has considerable solubility in $\mathrm{MgAl}_{2} \mathrm{O}_{4}$, and hence magnesia-enriched spinel formed at high temperature is expected to precipitate $\mathrm{MgO}$ from spinel. The microstructural evidence of precipitation of $\mathrm{MgO}$ in spinel is rarely available in the literature. The incorporation of a second phase in alumina improves the functional properties of alumina by altering the strength (creep rate), microstructure, deformation mechanism and fracture behaviour (Takigawa et al 1998; Kim et al 2001). Shiono et al (2000) also studied the deformation behaviour of fine grained magnesium aluminate spinel prepared by chemical route.

Structurally speaking, most stable form of alumina $(\alpha-$ alumina) has corundum structure and it is stable up to its melting point. The structure is based on hexagonal closed packing of oxygen ions in which $2 / 3 \mathrm{rd}$ of the octahedral sites are filled with aluminium ions. In spinel, the oxygen ions are cubically closed packed creating octahedral and tetrahedral voids. In such sites, $1 / 8$ th of the tetrahedral and $1 / 2$ of the octahedral voids are filled by $\mathrm{Mg}^{2+}$ and $\mathrm{Al}^{3+}$ ions, respectively. In spinel-alumina interaction at high temperatures, $\mathrm{Al}_{2} \mathrm{O}_{3}$ goes into solid solution in spinel by replacing three $\mathrm{Mg}^{2+}$ ions by two $\mathrm{Al}^{3+}$ ions. Ulti- 
mately, the end product is $\gamma$-alumina, which is also cubic in structure.

A combination of magnesia-spinel and alumina-spinel composites with a moderate range of porosity is used as high temperature structural materials. The refractory grade alumina-rich spinels containing up to $90 \mathrm{wt} \%$ alumina are commercially used in high alumina castables. The solid solubility of $\mathrm{Al}_{2} \mathrm{O}_{3}$ in spinel and its subsequent precipitation during actual operation play the vital role for improving the performance of alumina-spinel castables.

Therefore, in the present investigation, the interaction between alumina-enriched spinel and alumina was studied in the entire range of spinel-alumina composites. High temperature interaction between spinel and alumina has been expressed in terms of changes of different physical properties such as bulk density, percent apparent porosity, densification rate, etc with composition of the composites. The SEM results were analysed and also compared with previous work in order to understand the mechanism of interaction.

\section{Experimental}

\subsection{Sample preparation}

The refractory grade calcined alumina (with particle size below $15 \mu \mathrm{m}$ and purity, 99.6\%) and alumina-enriched spinel $\left[-300\right.$ B.S. sieve and purity $\left(\mathrm{Al}_{2} \mathrm{O}_{3}+\mathrm{MgO}\right)=99 \%$ ] were used for the present study. Both the raw materials were characterized in terms of chemistry by conventional wet chemical method (table 1) and particle size distribution by particle size analyser (table 2). Different batch compositions containing spinel and calcined alumina were prepared by mixing in an agate mortar. In each case, the batch size was $60 \mathrm{~g}$ and the mixing time was $30 \mathrm{~min}$. The details of batch compositions are given in table 3 .

A cylindrical high carbon steel mould of internal diameter $2.55 \mathrm{~cm}$ (approx.) was used for moulding green pellets at a forming pressure of $1550 \mathrm{~kg} \mathrm{~cm}^{-2}$ with the addition of appropriate amounts of organic binder and water. For each batch composition, six pellets were prepared. The 'green density' of pellets in all the batch compositions was measured from dimensions (diameter and thickness) and mass of the dried pellets (i.e. at $110^{\circ} \mathrm{C}$ for $24 \mathrm{~h})$.

Table 1. Chemical analysis of refractory grade calcined alumina and spinel $\left(\mathrm{MgAl}_{2} \mathrm{O}_{4}\right)$ powder [loss free basis].

\begin{tabular}{lcc}
\hline Constituents & Calcined $\mathrm{Al}_{2} \mathrm{O}_{3}($ wt $\%)$ & $\mathrm{MgAl}_{2} \mathrm{O}_{4}($ wt $\%)$ \\
\hline $\mathrm{Al}_{2} \mathrm{O}_{3}$ & 99.50 & $77 \cdot 40$ \\
$\mathrm{MgO}$ & Traces & 21.60 \\
$\mathrm{Na}_{2} \mathrm{O}$ & $0 \cdot 35$ & 0.28 \\
$\mathrm{Fe}_{2} \mathrm{O}_{3}$ & 0.06 & $0 \cdot 12$ \\
$\mathrm{SiO}_{2}$ & $0 \cdot 04$ & 0.04 \\
$\mathrm{CaO}$ & Traces & 0.28 \\
\hline
\end{tabular}

\subsection{Sintering}

Three temperatures, viz. $1500^{\circ}, 1550^{\circ}$ and $1600^{\circ} \mathrm{C}$, were chosen for sintering studies. Two green pellets of each batch were sintered at each temperature for an averaging procedure in order to have a statistical reliability of the data. The same heating schedule was followed as: $10^{\circ} \mathrm{C} \mathrm{min}^{-1}$ from room temperature to $1000^{\circ} \mathrm{C}$, and $5^{\circ} \mathrm{C} \mathrm{min}^{-1}$ from $1000^{\circ} \mathrm{C}$ to the respective sintering temperature. A soaking time of $2 \mathrm{~h}$ was given for sintering at each temperature. In each case, the furnace was forced to cool down to $800^{\circ} \mathrm{C}$, and then normal cooling was followed down to room temperature.

\subsection{Physical properties}

The density of the pellets sintered at different temperatures was measured from dimensions and mass of the pellets. The apparent porosity and bulk density of the pellets were measured by boiling method. There was hardly any difference between the measured values of densities by two methods. The firing shrinkage and percent densification during sintering were calculated from dimensions and density of green and fired pellets. Pycnometric densities of all the composites (A1 to A9) sintered at $1600^{\circ} \mathrm{C}$ were measured by following standard method.

Table 2. Particle size distribution of refractory grade calcined alumina and spinel.

\begin{tabular}{|c|c|c|}
\hline \multirow[b]{2}{*}{ Particle size $(\mu \mathrm{m})$} & \multicolumn{2}{|c|}{ Materials } \\
\hline & $\begin{array}{c}\text { Calcined } \mathrm{Al}_{2} \mathrm{O}_{3} \\
\text { (wt\% under) }\end{array}$ & $\begin{array}{c}\mathrm{MgAl}_{2} \mathrm{O}_{4} \\
\text { (wt\% under) }\end{array}$ \\
\hline $53 \cdot 5$ & $100 \cdot 0$ & $97 \cdot 5$ \\
\hline 37.6 & $100 \cdot 0$ & $77 \cdot 8$ \\
\hline $28 \cdot 1$ & $100 \cdot 0$ & $41 \cdot 2$ \\
\hline 21.5 & $100 \cdot 0$ & $20 \cdot 5$ \\
\hline $16 \cdot 7$ & $100 \cdot 0$ & $13 \cdot 2$ \\
\hline $13 \cdot 0$ & 98.4 & $5 \cdot 6$ \\
\hline $10 \cdot 1$ & $86 \cdot 5$ & $1 \cdot 2$ \\
\hline $7 \cdot 9$ & $69 \cdot 7$ & \\
\hline $4 \cdot 8$ & 33.9 & \\
\hline $3 \cdot 0$ & 7.7 & \\
\hline 1.9 & 1.9 & \\
\hline
\end{tabular}

Table 3. Batch compositions (batch size $60 \mathrm{~g}$ ).

\begin{tabular}{lcc}
\hline Batch number & Calcined $\mathrm{Al}_{2} \mathrm{O}_{3}(\mathrm{wt} \%)$ & $\mathrm{MgAl}_{2} \mathrm{O}_{4}(\mathrm{wt} \%)$ \\
\hline $\mathrm{A} 1$ & 0 & 100 \\
$\mathrm{~A} 2$ & 5 & 95 \\
$\mathrm{~A} 3$ & 10 & 90 \\
$\mathrm{~A} 4$ & 25 & 75 \\
$\mathrm{~A} 5$ & 50 & 50 \\
$\mathrm{~A} 6$ & 75 & 25 \\
$\mathrm{~A} 7$ & 90 & 10 \\
A8 & 96 & 4 \\
A9 & 100 & 0 \\
\hline
\end{tabular}


Table 4. Chemical compositions of different batches of spinel-alumina composites.

\begin{tabular}{lccc}
\hline & \multicolumn{3}{c}{ Chemistry } \\
\cline { 2 - 4 } Batch number & $\mathrm{Al}_{2} \mathrm{O}_{3}(\mathrm{wt} \%)$ & $\mathrm{MgO}(\mathrm{wt} \%)$ & $\begin{array}{c}\text { Impurities }(\mathrm{wt} \%) \\
\left(\mathrm{Fe}_{2} \mathrm{O}_{3}+\mathrm{Na}_{2} \mathrm{O}+\mathrm{SiO}_{2}+\mathrm{CaO}\right)\end{array}$ \\
\hline A1 & 77.40 & 21.60 & 1.00 \\
A2 & 78.51 & 20.52 & 0.97 \\
A3 & 79.61 & 19.44 & 0.95 \\
A4 & 82.92 & 16.20 & 0.88 \\
A5 & 88.45 & 10.80 & 0.75 \\
A6 & 93.98 & 5.40 & 0.62 \\
A7 & 97.29 & 2.16 & 0.55 \\
A8 & 98.62 & 0.86 & 0.52 \\
A9 & 99.50 & Nil & 0.50 \\
\hline
\end{tabular}

Table 5. Green density (dried at $110^{\circ} \mathrm{C}, 24 \mathrm{~h}$ ) of pellets of different batch compositions (forming pressure $=1550 \mathrm{~kg} \mathrm{~cm}^{-2}$ ).

\begin{tabular}{lccc}
\hline & \multicolumn{3}{c}{ Green densities $\left(\mathrm{g} \mathrm{cm}^{-2}\right)$} \\
\cline { 2 - 4 } Batch number & Maximum & Minimum & Average \\
\hline A1 & $2 \cdot 48$ & $2 \cdot 45$ & $2 \cdot 45$ \\
A2 & $2 \cdot 48$ & $2 \cdot 45$ & $2 \cdot 46$ \\
A3 & $2 \cdot 45$ & $2 \cdot 45$ & $2 \cdot 45$ \\
A4 & $2 \cdot 46$ & $2 \cdot 43$ & $2 \cdot 44$ \\
A5 & $2 \cdot 44$ & $2 \cdot 39$ & $2 \cdot 41$ \\
A6 & $2 \cdot 41$ & $2 \cdot 37$ & $2 \cdot 39$ \\
A7 & $2 \cdot 40$ & $2 \cdot 34$ & $2 \cdot 35$ \\
A8 & $2 \cdot 30$ & $2 \cdot 26$ & $2 \cdot 29$ \\
A9 & $2 \cdot 26$ & $2 \cdot 23$ & $2 \cdot 24$ \\
\hline
\end{tabular}

\subsection{Microstructural studies}

Scanning electron microscopic (SEM) studies were conducted on fractured surfaces of the samples (A1 to A8, sintered at $1600^{\circ} \mathrm{C}$ for $2 \mathrm{~h}$ ) coated with gold in JEOL5200 scanning electron microscope operated at $15 \mathrm{kV}$.

\section{Results and discussion}

\subsection{Characterization of powders}

The chemical analyses of calcined alumina and spinel powder (table 1) indicates 99.5 and $99 \%$ purity, respectively. It is expected that sintering of either spinel or alumina or combinations of spinel-alumina admixture will be accompanied by solid state sintering. Their particle size distribution (table 2) reveals that fineness of powders are in sub-sieve but not sub-micron range, and they will not be so much interactive to give enhanced densification (near theoretical) at $1500-1600^{\circ} \mathrm{C}$ temperature range.

The chemical compositions of all the batches containing alumina and spinel were calculated (table 4) based on chemistry of calcined alumina and spinel (table 1). The chemistry of spinel-alumina composites (A1 to A8) reveals that each composite is a combination of spinel and corundum ( $\alpha$-alumina) phase. The green densities of spinel and alumina powders formed at identical forming pressure $\left(1550 \mathrm{~kg} \mathrm{~cm}^{-2}\right)$ are 2.45 and $2.24 \mathrm{~g} \mathrm{~cm}^{-3}$, respectively although alumina has a higher specific gravity (3.95) than spinel (3.638). It is pertinent to note that the lower green density may be due to the presence of considerable amount of 'inter-granular open voids' (not deformable during forming) in calcined alumina as compared to spinel. This results in gradual reduction of green density with increase in alumina content in the 'spinel compositions' (table 5). True specific gravity of each batch composition of sintered pellets $\left(1600^{\circ} \mathrm{C}, 2 \mathrm{~h}\right)$ was measured by pycnometric method and reported in table 6 .

\subsection{Physical characteristics}

For better understanding of the mechanism of spinelalumina interaction at different temperatures $\left(1500^{\circ}\right.$, $1550^{\circ}$ and $1600^{\circ} \mathrm{C}$ ), different parameters related to sintering, viz. fired density, percent apparent porosity, percent firing shrinkage (i.e. volume shrinkage), percent closed pores and percent densification with respect to green density were plotted against wt $\%$ alumina that was added in the 'spinel composite'.

The spinel powder used for the present investigation contained around $22 \mathrm{wt} \% \alpha$-alumina and $77 \mathrm{wt} \%$ stoichiometric magnesium aluminate spinel. Phase compositions of composites were calculated in terms of stoichiometric magnesium aluminate spinel and excess $\alpha$-alumina from chemical composition of composites. Phase compositions and their correlation with \% open pores, closed pores and apparent specific gravity of composites have been specified in table 7. An addition of 5-10 wt \% alumina in spinel causes considerable increase in sintered bulk density at all sintering temperatures (figure 1).

Further addition of alumina causes gradual decrease in the bulk density, which is unexpected since true specific gravity of alumina is greater than spinel. The sintered density of pellets made of only calcined alumina gives lower value, which reveals that calcined alumina is not so 
Table 6. True specific gravity and \% true porosity of different spinel-alumina composites.

\begin{tabular}{|c|c|c|c|c|}
\hline \multirow[b]{2}{*}{ Batch number } & \multirow{2}{*}{$\begin{array}{l}\text { True specific } \\
\text { gravity (TSG) }\end{array}$} & \multicolumn{3}{|c|}{$\%$ True porosity $(100(\mathrm{TSG}-\mathrm{BD}) / \mathrm{TSG})$} \\
\hline & & $1500^{\circ} \mathrm{C}, 2 \mathrm{~h}$ & $1550^{\circ} \mathrm{C}, 2 \mathrm{~h}$ & $1600^{\circ} \mathrm{C}, 2 \mathrm{~h}$ \\
\hline A1 & $3 \cdot 6380$ & $29 \cdot 08$ & $26 \cdot 06$ & $23 \cdot 03$ \\
\hline A2 & $3 \cdot 6610$ & $24 \cdot 61$ & $22 \cdot 70$ & $15 \cdot 32$ \\
\hline A3 & $3 \cdot 6762$ & $27 \cdot 37$ & $23 \cdot 29$ & $19 \cdot 75$ \\
\hline A4 & $3 \cdot 7218$ & $30 \cdot 14$ & $28 \cdot 53$ & $22 \cdot 62$ \\
\hline A5 & 3.7979 & $32 \cdot 86$ & 32.07 & $26 \cdot 27$ \\
\hline A6 & 3.8739 & $34 \cdot 69$ & $34 \cdot 17$ & $29 \cdot 01$ \\
\hline A7 & 3.9196 & $36 \cdot 73$ & $35 \cdot 71$ & $32 \cdot 39$ \\
\hline A8 & 3.9378 & $39 \cdot 56$ & $38 \cdot 04$ & $33 \cdot 47$ \\
\hline A9 & $3 \cdot 9500$ & $40 \cdot 76$ & 38.99 & $33 \cdot 92$ \\
\hline
\end{tabular}

Table 7. Relation among phase composition and \% open pores, $\%$ closed pores and apparent specific gravity of spinel-alumina composites at $1600^{\circ} \mathrm{C}$ for $2 \mathrm{~h}$ soaking time.

\begin{tabular}{|c|c|c|c|c|c|}
\hline \multirow[b]{2}{*}{ Batch no. } & \multicolumn{2}{|c|}{ Phase composition (wt\%) } & \multirow[b]{2}{*}{$\begin{array}{c}\text { Apparent } \\
\text { specific gravity }\end{array}$} & \multirow[b]{2}{*}{$\%$ Open pores } & \multirow[b]{2}{*}{$\%$ Closed pores } \\
\hline & $\begin{array}{l}\text { Stoichiometric } \\
\text { spinel }\end{array}$ & $\begin{array}{c}\text { Excess } \\
\alpha \text {-alumina }\end{array}$ & & & \\
\hline Al & $76 \cdot 68$ & $22 \cdot 32$ & $3 \cdot 542$ & $20 \cdot 94$ & $2 \cdot 26$ \\
\hline $\mathrm{A} 2$ & $72 \cdot 91$ & $26 \cdot 19$ & $3 \cdot 55$ & $12 \cdot 68$ & $2 \cdot 64$ \\
\hline A3 & $69 \cdot 01$ & $30 \cdot 04$ & $3 \cdot 445$ & $14 \cdot 37$ & $5 \cdot 38$ \\
\hline A4 & $57 \cdot 51$ & $41 \cdot 31$ & $3 \cdot 516$ & $18 \cdot 1$ & $4 \cdot 52$ \\
\hline A5 & $38 \cdot 34$ & $60 \cdot 91$ & 3.565 & 21.45 & $4 \cdot 83$ \\
\hline A6 & $19 \cdot 17$ & $80 \cdot 21$ & 3.606 & $23 \cdot 73$ & $5 \cdot 28$ \\
\hline A7 & $7 \cdot 67$ & 91.78 & $3 \cdot 727$ & 28.89 & $3 \cdot 5$ \\
\hline A8 & 3.05 & $96 \cdot 43$ & 3.784 & $30 \cdot 76$ & $2 \cdot 71$ \\
\hline A9 & - & $99 \cdot 5$ & $3 \cdot 835$ & $31 \cdot 94$ & $2 \cdot 91$ \\
\hline
\end{tabular}

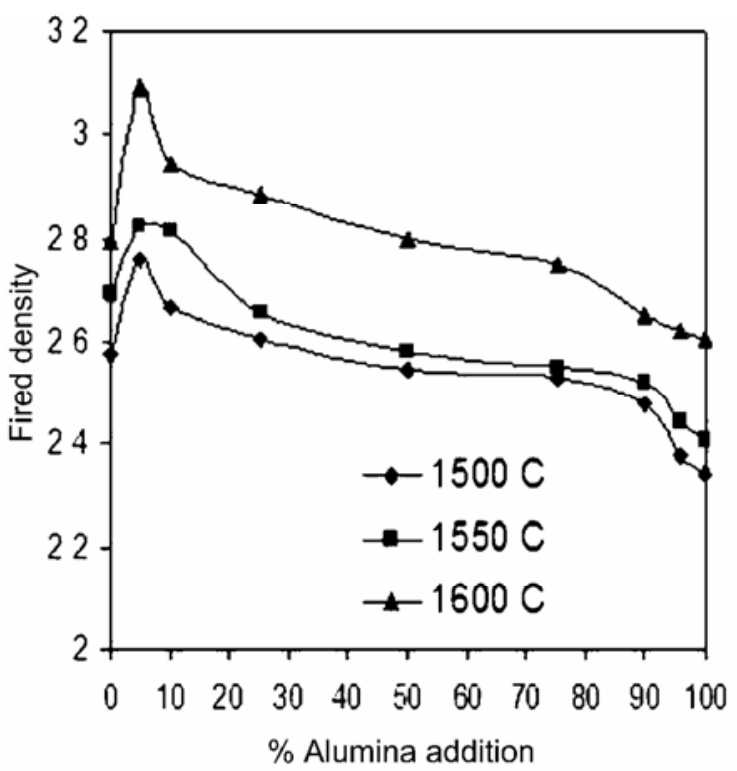

Figure 1. Variation of fired density of spinel-alumina composites with addition of alumina at different temperatures $(2 \mathrm{~h}$ soaking time).

reactive by itself. Since true specific gravity of different batches gradually increases with addition of alumina, it is expected that the marginal decrease in bulk density will be reflected to a greater extent in an increase of percent apparent porosity (\%AP) and percent true porosity $(\% \mathrm{TP})$.
The addition of alumina to a certain extent (5-10 wt\%) in spinel causes decrease in both \%AP (figure 2) and \%TP (table 6) of spinel-alumina composites. The addition of 5-10 wt\% alumina causes maximum reduction both in \% AP and \% $\mathrm{TP}$ of composites at all temperatures from $1500-1600^{\circ} \mathrm{C}$. At $1600^{\circ} \mathrm{C}$, the porosities (both \%AP and $\% \mathrm{TP}$ ) of the composites are lower than spinel-based composite up to $25 \mathrm{wt} \%$ addition of alumina. At higher $w t \%$, addition of alumina, the porosity gradually increases with the amount of addition of alumina. Figure 3 shows the variation of percent closed pores with $w t \%$ alumina addition. It is observed that all the composites have closed pores at all the temperatures, and its value increases in the composition range having $10-90 \mathrm{wt} \%$ addition of alumina.

Composites containing around $70 \mathrm{wt} \%$ to around $20 \mathrm{wt} \%$ spinel have higher percentage of closed pores (table 7). Solid solution of alumina in spinel at $1600^{\circ} \mathrm{C}$ and its precipitation during cooling are complex phenomena. This may be due to complete precipitation of $\alpha$-alumina from spinel structure in the above composition range, which will cause increase of both open and closed pores. The variations of percent volume shrinkage and percent densification (with respect to green density) with wt\% alumina (figures 4 and 5) show the same trend, as is observed in the case of bulk density vs wt $\%$ alumina plot. 


\subsection{Microstructural studies}

Microstructural inhomogeneity was observed in SEM images (figure 6) of most of the composites made by the interaction of spinel and alumina at $1600^{\circ} \mathrm{C}$. Evidence of void formation due to acicular inhomogeneity in synthetic spinel was studied by Arnold (1960). Here composite A1 is made of admixture of stoichiometric spinel and

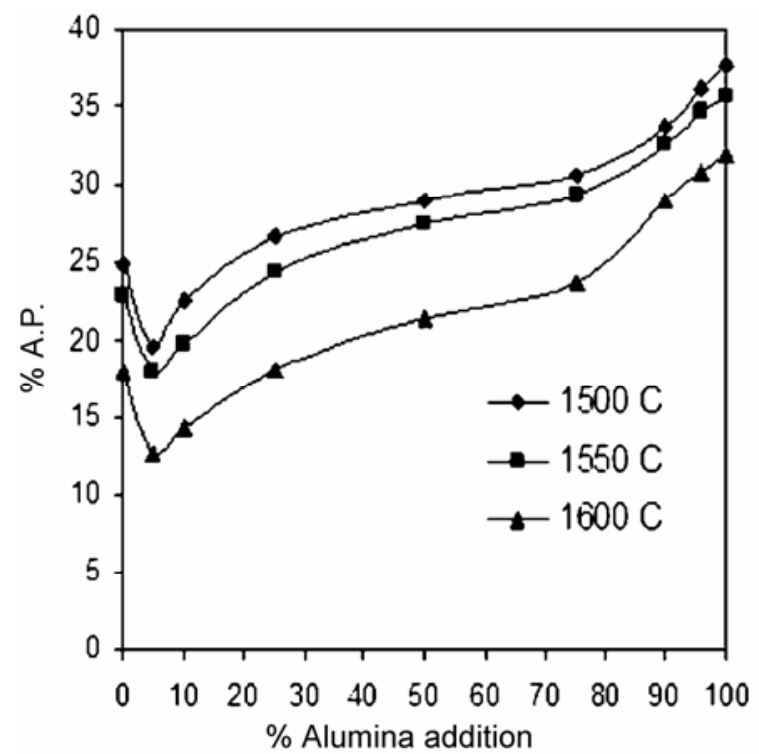

Figure 2. Variation of apparent porosity (AP) of spinelalumina composites with addition of alumina at different temperatures ( $2 \mathrm{~h}$ soaking time).

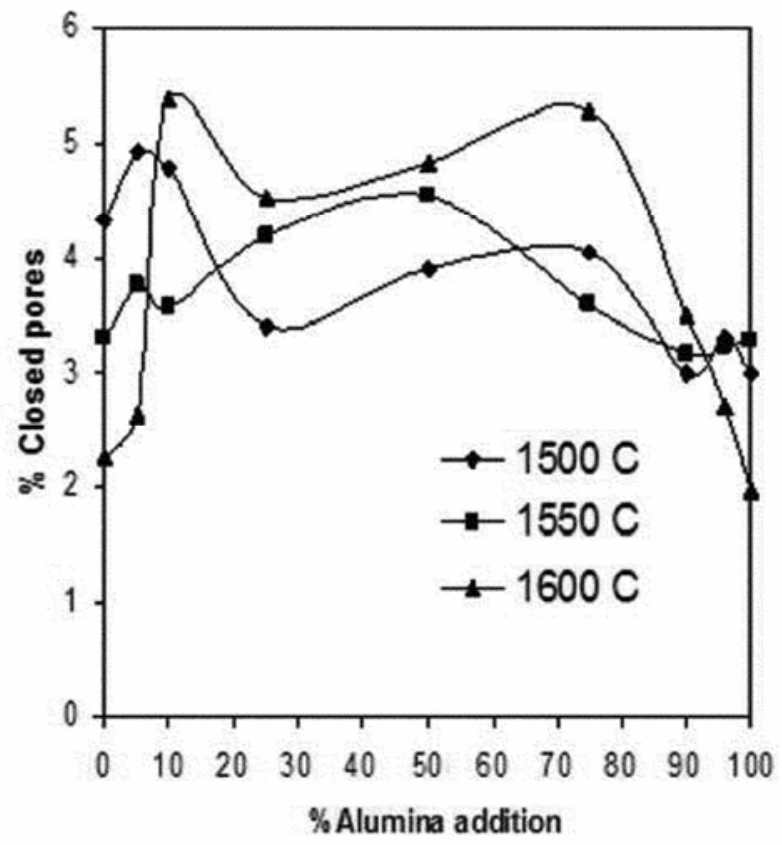

Figure 3. Variation of $\%$ closed pores of spinel-alumina composites with addition of alumina at different temperatures $(2 \mathrm{~h}$ soaking time). alumina. Dissolution of alumina from spinel lattice structure is dependent on thermal cycle of spinel-alumina interaction. Dual microstructure is seen even in spinelbased composite (figure 6A1) where some spinel grain surfaces are clean and most are roughened by precipitation of $\alpha$-alumina from spinel lattice. The extent of surface roughening due to precipitation of fine alumina gradually increases up to $25 \mathrm{wt} \%$ addition of alumina in

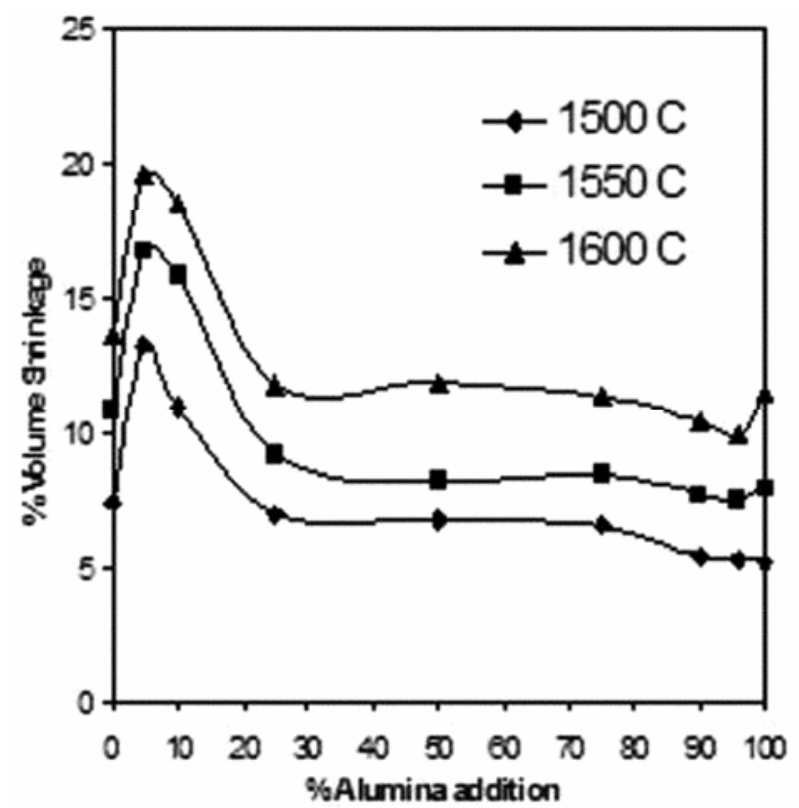

Figure 4. Variation of volume shrinkage of spinel-alumina composites with addition of alumina at different temperatures ( $2 \mathrm{~h}$ soaking time).

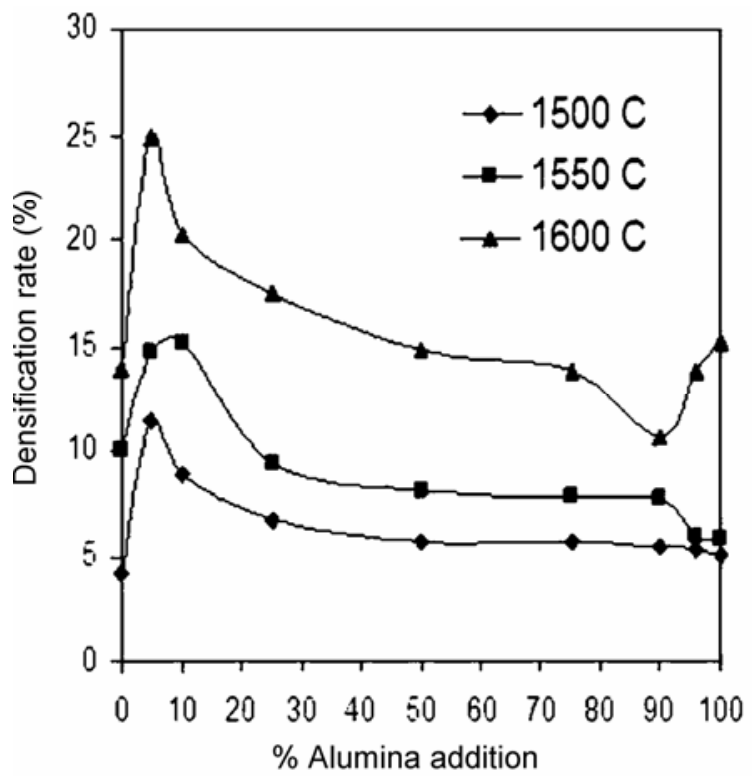

Figure 5. Variation of densification rate (\%) of spinelalumina composites with addition of alumina at different temperatures ( $2 \mathrm{~h}$ soaking time). 

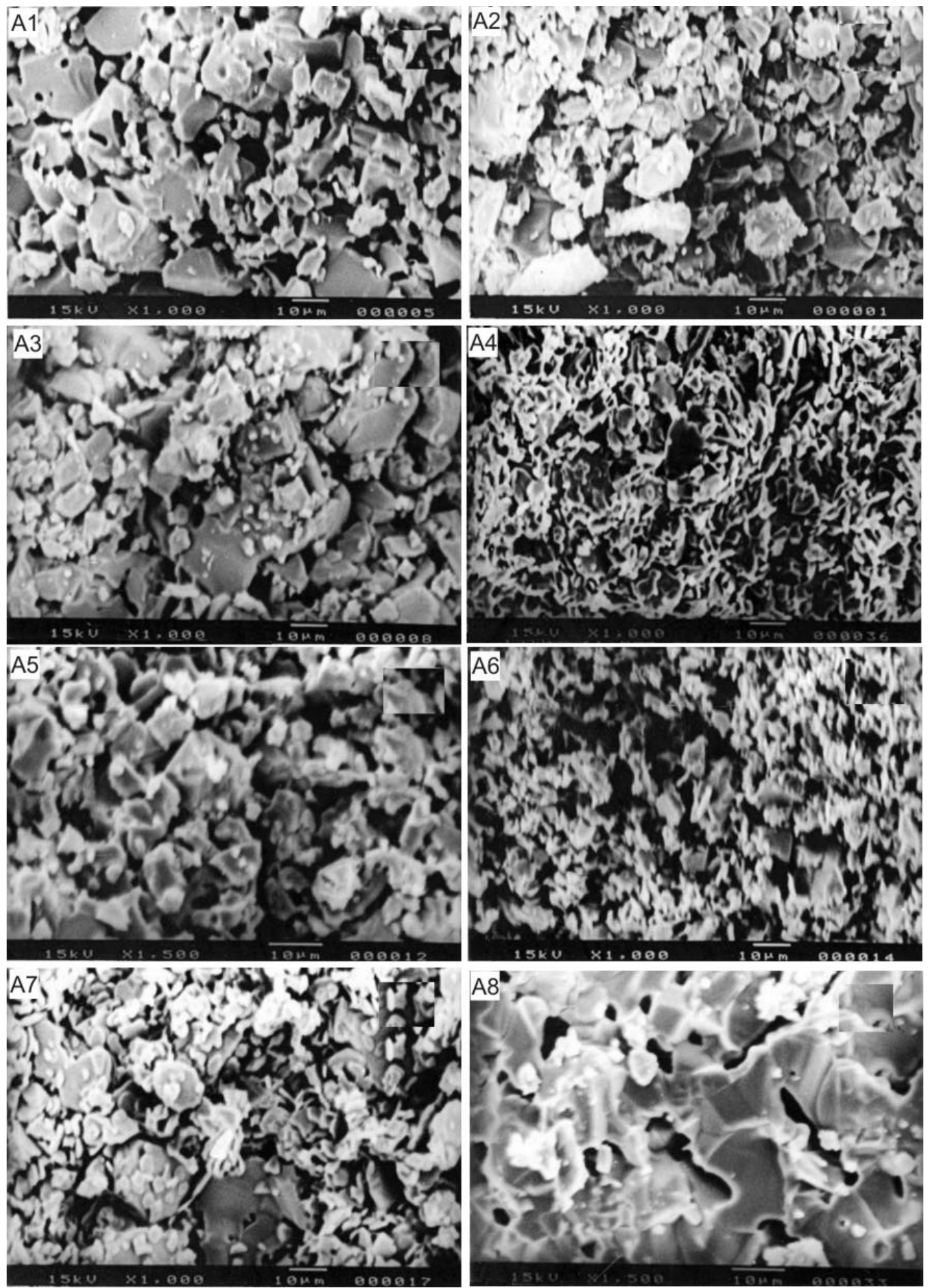

Figure 6. SEM photographs of fractured surface of spinel-alumina composites (figures 6A1-6A8) sintered at $1600^{\circ} \mathrm{C}$ for $2 \mathrm{~h}$. (Here, A1 to A8 refer to the batch compositions as specified in tables $3-7$ ).

spinel (figures 6A2-6A4). On the other hand, addition of spinel in alumina has positive effects in improvement of physical properties such as increase in bulk density and decrease in porosity, etc of alumina-spinel composites. In the present work, alumina-spinel composites do not have distinct precipitation of $\alpha$-alumina and lack development of interlocking structures. Previous work of one of the authors (Paul 1986) may be reproduced (figures 7a-d) to show the development of interlocking structures when submicron mono-size $(0 \cdot 3-0.4 \mu \mathrm{m})$ alumina powder 

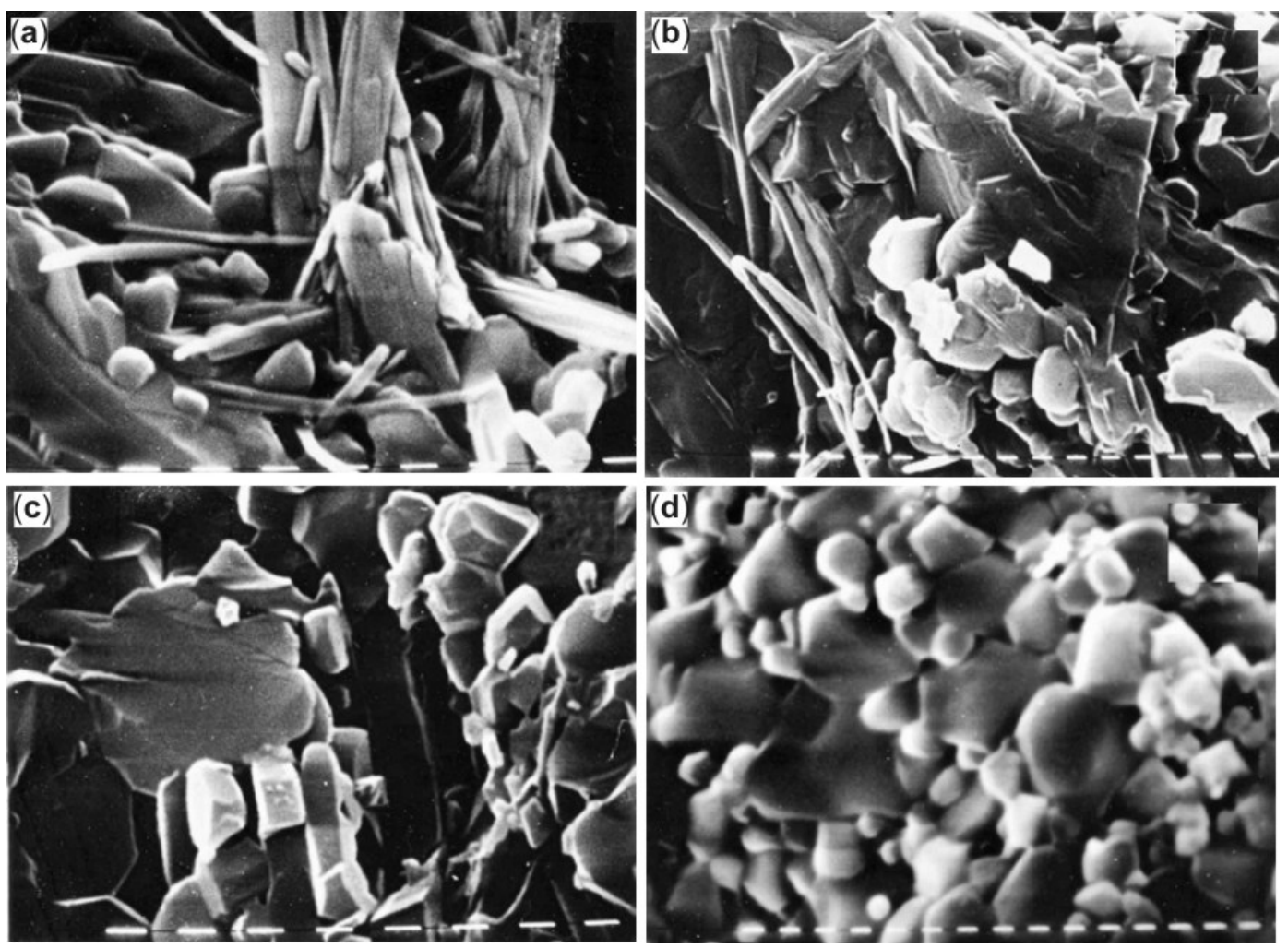

Figure 7. SEM photographs of fractured surfaces of alumina-spinel composites sintered at $1600^{\circ} \mathrm{C}, 2 \mathrm{~h}$ soaking (each dash indicates $1 \mu \mathrm{m}$ ): (a) $85 \mathrm{wt} \%$ alumina and $15 \mathrm{wt} \%$ spinel, (b) $75 \mathrm{wt} \%$ alumina and $25 \mathrm{wt} \%$ spinel, (c) $50 \mathrm{wt} \%$ alumina and $50 \mathrm{wt} \%$ spinel, and (d) $100 \mathrm{wt} \%$ spinel (reprinted with permission from Paul 1986).

interacted with chemically prepared phase pure magnesium aluminate spinel. Distinct needle form precipitation of $\alpha$-alumina (figures $7 \mathrm{a}$ and $\mathrm{b}$ ) can be seen when addition of spinel is in the $15-25 \mathrm{wt} \%$ range. However, in case of 50-50 wt\% spinel-alumina composite, this needle like precipitation of $\alpha$-alumina is not visible and both spinel and alumina grains are distinctly noticeable in the microstructure. Phase pure sintered spinel $\left(1600^{\circ} \mathrm{C}\right.$, $2 \mathrm{~h}$ ) shows cubical morphology of spinel (figure $7 \mathrm{~d}$ ). In the present work, abnormal grain growth in sintered alumina and distinct precipitation of $\alpha$-alumina in the composites are not noticeably visible mostly due to coarser granulometry of both alumina and spinel powder as compared to the finer granulometry of the previous work.

Further dissolution of alumina in spinel during heat treatment and subsequent precipitation of $\alpha$-alumina during cooling are complex processes. This results in generation of both open and closed pores. Also, creation of open pores may be due to stress exerted by precipitated alumina at grain boundary/matrix. Voids created by precipitation process of $\alpha$-alumina from spinel structure are not completely opened up. It happened mostly in the composites $A_{3}$ to $A_{6}$ causing higher percentage of closed pores. True specific gravity of spinel-alumina composite depends on its phase composition as evidenced by true specific gravity of the composites (table 6). Suwa et al (1986) studied the interaction between chemically pure alumina and magnesia (93:7 wt ratio) gel and observed that the complete phase separation of $\alpha$-alumina and spinel took place from composite containing $\gamma$-alumina and spinel admixture in the form of solid solution at $1100^{\circ} \mathrm{C}$ for $100 \mathrm{~min}$ soaking time.

Literature (Rinne 1928) is available where it has been shown that spinel having higher stoichiometry of alumina (92.7 wt \% alumina) has marginally higher specific gravity $(3.624)$ than stoichiometric spinel $(3.578)$, and this behaviour is absolutely abnormal. It is only possible if dissolved alumina is retained in spinel lattice structure at room temperature. SEM photographs (figures 6A4-6A6) of present study having the compositions of spinel: alumina $=60: 40$ to $20: 80$ (table 7 ) have needle like precipitation of $\alpha$-alumina. Morphology of composite having spinel: alumina (approximate wt ratio $40: 60$ ) (figure 6A5) is different from that of the spinel: alumina having a wt ratio of $60: 40$ (figure 6A4) or $20: 80$ (figure 6A6). Secondary grain growth is observed in alumina body (figure $6 \mathrm{~A} 8$ ), containing around $3 \mathrm{wt} \%$ spinel (table 7 ), which is also abnormal. This may be due to heterogeneous incorporation of spinel in alumina. 


\section{Conclusions}

The solid solution and precipitation mechanism due to spinel-alumina interaction may be used as a basic model to develop spinel-alumina or alumina-spinel composites. The spinel can retain some amount of alumina in its host structure even at room temperature, which may be exolved as $\alpha$-alumina during use, thus forming an interlocking structure between two types of (alumina and spinel) grains. This type of microstructural feature is consistent with the trends in the improvement of physical properties such as $\% \mathrm{AP}, \mathrm{BD}, \% \mathrm{TP}$, etc of spinel by the addition of alumina, as observed in the present investigation. Further work is in progress to develop spinel based dense composites with the addition of alumina for various industrial applications.

\section{References}

Arnold H 1960 Z. Krist. 11423

Burke J E, Lay K W and Prochazka S 1980 Sintering process sci. res. (ed.) Kuczynski (New York and London: G C Plenum Press) 13 p. 417
Coble R L 1961 J. Appl. Phys. 32793

Greskovitch C and Anthony Brewer J 2001 J. Am. Ceram. Soc. 84420

Hener A H 1979 J. Am. Ceram. Soc. 62317

Kim B N, Hiraga K, Morita K and Sakka Y 2001 Acta Mater. 49887

Kingery W D, Bowen H K and Uhlmann D R 1976 Introduction to ceramics (New York: John Wiley \& Sons Inc.) 2nd ed. pp. 131-133

Kingery W D 1960 Introduction to ceramics (New York: John Wiley \& Sons Inc.) p. 264

Paul P G 1986 Study of sintering kinetics of alumina in presence of magnesio-aluminate spinel, $\mathrm{Ph} \mathrm{D}$ Thesis, University of Calcutta, Kolkata

Paul P G and Samaddar B N 1985 Trans. Ind. Ceram. Soc. 44 132

Rinne F 1928 Neues Jahrb. Mineral Geol Beib Bd. $\mathbf{A 5 8}$ 43

Shiono T, Ishitomi H, Okamoto Y and Nishida T $2000 \mathrm{~J}$. Am. Ceram. Soc. 83645

Suwa Y, Roy R and Komarneni S 1986 Mater. Sci. \& Eng. 83 151

Takigawa Y, Yoshizawa Y and Sakume T 1998 Ceram. Int. 24 61 